\title{
Addiction to Sex and/or Pornography: A Position Statement from the Center for Positive Sexuality (CPS), The Alternative Sexualities Health Research Alliance (TASHRA), and the National Coalition for Sexual Freedom (NCSF)
}

Over the last 30 years, there has been a slow but growing acceptance among some academics, professionals, policymakers, media, and members of the public regarding the popular concept of addiction to sex and/or pornography (Irvine, 1993, 1995; Reay, Attwood, \& Gooder, 2013; Ley, Prause, \& Finn, 2014; Voros, 2009). Although some academic and professional reports have supported the application of an addiction model to frequent sexual behavior and/or pornography viewing (i.e., Hilton \& Watts, 2011; Kafka, 2010), others point out serious potential or actual problems with applying an addiction model to sexual behavior and pornography viewing (Ley, 2012; Ley, Prause, \& Finn, 2014; Reid \& Kafka, 2014; Giugliano, 2009; Hall, 2014; Karila et al., 2014; Moser, 2013; Kor, Fogel, Reid, \& Potenza, 2013; Ley et al., 2014; Prause \& Fong, 2015; Prause, Steele, Staley, Sabatinelli, \& Hajcak, 2015). Despite serious disagreement among scholars, the concept of sex/porn addiction frequently is applied across multiple professional contexts, including various legal settings (Ley, Brovko, \& Reid, 2015).

Based on existing research and scholarship, the Center for Positive Sexuality (CPS), The Alternative Sexualities Health Research Alliance (TASHRA), and the National Coalition for Sexual Freedom (NCSF) strongly oppose the addiction model when considering pornography viewing and frequent sexual behavior. Reasons for this opposition include:

(a) The American Psychiatric Association (APA) does not identify sex/porn addiction as mental disorders. Similarly, the American Association of Sexuality Educators, Counselors, and Therapists (AASECT) does not recognize sex/porn addiction as mental disorders and has concluded that an addiction model "cannot be advanced as a standard of practice for sexuality education delivery, counseling, or therapy" (AASECT, 2017).

(b) Existing studies supporting an addiction model lack precise definitions and methodological rigor, and rely on correlational data. Pre-existing psychological issues that could account for changes in sexual behavior and/or pornography viewing have not been considered. Studies are needed that utilize experimental designs and account for a range of potential extraneous variables (Ley et al., 2014). Although some people may incorrectly assume that increased dopaminergic activity during sex or pornography viewing (which is to be expected) is evidence for addiction, Prause, Steele, Staley, Sabatinelli, and Hajcak (2015) found in their controlled study that participants reporting hypersexual problems did not show the same neural response patterns consistent with other known addictions. There are many diverse reasons why people may engage in pornography viewing, and frequent and diverse sexual activities, which must be considered when assessing behavior (Ley, 2012; Ley et al., 2014).

(c) The sex/porn addiction model reflects significant sociocultural biases (Klein, 2002; Williams, 2016), including specific measures of clinical assessment (Joannides, 2012). Socio-cultural biases include assumptions concerning normal sex drive, relationship styles, and erotic interests and practices. Thus, people with 
alternative sexual identities are likely to face further marginalization and discrimination by those who support a sex/porn addiction model.

(d) Research has shown that religiosity and moral disapproval have a strong influence on perceived sex/porn addiction. For example, Grubbs and colleagues (2010, 2015) found that religiosity and moral disapproval were strong predictors of perceived pornography addiction, even when actual pornography use was controlled. Other researchers have reported similar findings (Abell, Steenbergh, \& Boivin, 2006; Kwee, Dominguez, \& Ferrell, 2007; Leonhardt, Willoughby, \& Young-Petersen, 2017). Regarding pornography use, Thomas $(2013,2016)$ applied archival analysis to trace the creation and deployment of the addiction framework among evangelical Christians. Other scholars have reported that the concept of sex addiction emerged in the 1980s as a socially conservative response to cultural anxieties, and has gained acceptance through its reliance on medicalization and popular culture visibility (Reay, Attwood, \& Gooder, 2013; Voros, 2009).

(e) The sex/porn addiction model assumes that sexual behaviors as a coping mechanism are an indicator of addiction, but it does not consider the possibility that sex may be a positive coping mechanism. However, scholars have realized that various sexual and erotic activities may function as legitimate leisure experience, which can be salubrious, rather than necessarily maladaptive, ways of coping (i.e., Berdychevsky \& Nimrod, 2016; McCormick \& Wignall, 2016; Meaney \& Rye, 2007; Mock \& Hummel, 2012; Mock, Plante, Reysen, \& Gerbasi, 2013; Williams, Prior, Alvarado, Thomas, \& Christensen, 2016). Indeed, sexuality scholars have recognized the need to expand professional understanding of sexuality and the importance of diversity and pleasure as pertaining to individual health (i.e., Anderson, 2013; Diamond \& Huebner, 2012; Hull, 2008; Satcher, Hook III, \& Coleman, 2015).

CPS, TASHRA, and NCSF recognize that many people may struggle with sexual issues, including issues that occur within their committed relationships, which are valid reasons for seeking professional help. We also believe that helping professionals should, as appropriate, seek to support client-initiated behavioral change in healthful ways that are consistent with clients' moral beliefs and worldviews. However, existing multidisciplinary scholarship does not warrant the application of an addiction model to frequent sexual behavior and/or pornography viewing. Thus, regarding such behavior, use of the term "addiction" is not valid and may be misleading and sometimes harmful to clients. Helping professionals can effectively help clients who may be struggling with various sexual issues or problems by working from a positive sexuality perspective that utilizes multidisciplinary scholarship; applies high quality empirical research and critical analysis; and prioritizes sexual rights, diversity, and acceptance of a wide range of sexual interests, behaviors, and identities. 


\section{References}

Abell, J. W., Steenbergh, T. A., \& Boivin, M. J. (2006). cyberporn use in the context of religiosity. Journal of Psychology and Theology, 34, 165-171.

American Association of Sexuality Educators, Counselors, and Therapists. (2017). AASECT position on sex addiction. Washington, DC: Author. Retrieved from: www.aasect.org/position-sex-addiction

Anderson, R. M. (2013). Positive sexuality and its impact on overall wellbeing. Bundesgesundheitsblatt, 56, 208-214.

Berdychevsky, L, \& Nimrod, G. (2016). Sex as leisure in later life: A netnographic approach. Leisure Sciences (Advance access).

Diamond, L., \& Huebner, D. M. (2012). Is good sex good for you? Rethinking sexuality and health. Social and Personality Psychology Compass, 6, 54-69.

Giugliano, J. R. (2009). Sexual addiction: Diagnostic problems. International Journal of Mental Health and Addiction, 7, 283-294. doi:10.1007/s11469-0099195-3

Grubbs, J. B., Sessoms, J., Wheeler, D. M., \& Volk, F. (2010). The cyber-pornography use inventory: The development of a new assessment instrument. Sexual Addiction and Compulsivity, 17, 106-126.

Grubbs, J. B., Exline, Pargament, K. I., Hook, J. N., \& Carlisle, R. D. (2015).

Transgression as addiction: Religiosity and moral disapproval as predictors of perceived addiction to pornography. Archives of Sexual Behavior, 44, 125-136.

Hall, P. (2014). Sex addiction-An extraordinarily contentious problem. Sexual and Relationship Therapy, 29, 68-75. doi:10.1080/14681994.2013.861898

Hilton, D., \& Watts, C. (2011). Pornography addiction: A neuroscience perspective. Surgical Neurology International, 2, 19.

Hull, T. H. (2008). Sexual pleasure and wellbeing. International Journal of Sexual Health, 20,133-145.

Kafka, M. (2010). Hypersexual disorder: A proposed diagnosis for $D S M-V$. Archives of Sexual Behavior, 39, 377-400.

Irvine, J. M. (1993). Regulated passions: The invention of inhibited sexual desire and sex addiction. Social Text, 37, 203-226. doi:10.2307/466269
Irvine, J. M. (1995). Reinventing perversion: Sex addiction and cultural anxieties. Journal of the History of Sexuality, 5, 429-450.

Joannides, P. (2012). The challenging landscape of problematic sexual behaviors, including "sexual addiction" and "hypersexuality." In P. Kleinplatz (Ed.), New directions in sex therapy: Innovations and alternatives (pp. 69-84). New York, NY: Routledge.

Karila, L., Wery, A., Weinstein, A., Cottencin, O., Petit, A., Reynaud, M., \& Billieux, J. (2014).

Sexual addiction or hypersexual disorder: Different terms for the same problem? A review of the literature. Current Pharmaceutical Design, 20, 4012-4020.

Klein, M. (2002). Sex addiction: A dangerous clinical concept. In Electronic Journal of Human Sexuality, volume 5.

Kor, A., Fogel, Y. A., Reid, R. C., \& Potenza, M. N. (2013). Should hypersexual disorder be classified as an addiction? Sexual Addiction \& Compulsivity, 20, 27-47. doi:10.1080/10720162.2013.768132

Kwee, A. W., Dominguez, A. W., \& Ferrell, D. (2007). Sexual addiction and Christian college men: Conceptual, assessment, and treatment challenges. Journal of Psychology and Christianity, 26, 3-13.

Leonhardt, N. D., Willoughby, B. J., \& YoungPetersen, B. (2017). Damaged Goods: Perception of Pornography Addiction as a Mediator Between Religiosity and Relationship Anxiety Surrounding Pornography Use. The Journal of Sex Research, 1-12.

Ley, D. (2012). The myth of sex addiction. Lanham, MD: Rowman \& Littlefield.

Ley, D., Brovko, J. M., \& Reid, R. (2015). Forensic applications of "sex addiction" in US legal proceedings. Current Sexual Health Report, 7, 108-116.

Ley, D., Prause, N., \& Finn, P. (2014). The emperor has no clothes: A review of the "pornography addiction" model. Current Sexual Health Report, 6, 94-105.

McCormick, M., \& Wignall, L. (2016). Enjoyment, exploration and education: Understanding the consumption of pornography among young men with non-exclusive sexualorientations. Sociology (Advance access). 
Meaney, G. J., \& Rye, B. J. (2007). Sex, sexuality, and leisure. In R. McCarville \& K. MacKay (Eds.), Leisure for Canadians (pp. 135-144). State College, PA: Venture.

Mock, S. E., \& Hummel, E. M. (2012). Sexual minority adults at a seasonal home campground: An examination of common, unique, and diverse leisure motivations. Leisure Sciences,34, 155-171.

Mock, S. E., Plante, C. N., Reysen, S., \& Gerbasi, K. C. (2013). Deeper leisure involvement as a coping resource in a stigmatized leisure context. Leisure / Loisir, 37(2), 111-126.

Moser, C. (2013). Hypersexual disorder: Searching for clarity. Sexual Addiction \& Compulsivity, 20, 48-58. doi:10.1080/10720162.2013.775631

Prause, N., \& Fong, T. (2015). The science and politics of sex addiction research. In L. Comella \& S. Tarrant (Eds.), New views on pornography: Sexuality, politics, and the law (pp. 431-445). Santa Barbara, CA: Praeger.

Prause, N., Steele, V. R., Staley, C., Sabatinelli, D., \& Hajcak, G. (2015). Modulation of late positive potentials by several images in problem users and controls consistent with "porn addiction." Biological Psychology, 109, 192-199.

Reay, B., Attwood, N, \& Gooder, C. (2013). Inventing sex: The short history of sex addiction. Sexuality and Culture, 17, 1-19.

Reid, R. C., \& Kafka, M. (2014). Controversies about hypersexual disorder and $D S M-V$.
Current Sexual Health Report, 6, 259264.

Satcher, D., Hook III, E. W., \& Coleman, E. (2015). Sexual health in America: Improving patient care and public health. Journal of the American Medical Association, 314, 765-766.

Thomas, J. N. (2013). Outsourcing moral authority: The internal secularization of evangelicals' anti-pornography narratives. Journal for the Scientific Study of Religion, 52, 457-475. doi:10.1111/jssr.12052

Thomas, J. N. (2016). The development and deployment of the idea of pornography addiction within American evangelicalism. Sexual Addiction and Compulsivity, 23, 182-195.

Williams, DJ. (2016). The framing of frequent sexual behavior and/or pornography viewing as addiction: Some concerns for social work. Journal of Social Work (Advance access).

Williams, DJ, Prior, E. E., Alvarado, T., Thomas, J. N., \& Christensen, M. C. (2016). Is bondage and discipline, dominance and submission, and sadomasochism recreational leisure? A descriptive exploratory investigation. Journal of Sexual Medicine, 13, 1091-1094.

Voros, F. (2009). The invention of addiction to pornography. Sexologies, 18, 243-246. 